\title{
ESOncofisio
}

\section{Photobiomodulation and manual lymph drainage for the treatment of nipple necrosis in breast cancer patient: a case report}

\author{
Jaqueline Munaretto Timm Baiocchi ${ }^{1}$; Glauco Baiocchi ${ }^{2}$; Larissa Louise Campanholi ${ }^{3}$ \\ 1-Instituto Oncofisio (São Paulo, Brazil) \\ 2-Ac Camargo Cancer Center (São Paulo, Brazil) \\ 3 Instituto Sul Paranaense de Oncologia (Ponta Grossa, Brazil)
}

\section{INTRODUCTION}

The therapy of photobiomodulação, formerly known as low-level laser therapy (LLLT), demonstrated to promote repair of tissues, by cellular repair biostimulation, angiogenesis and anti-inflammatory effects. These characteristics suggest a potential role for repair of chronic wounds and that may be applicable in the treatment of necrosis.

In this perspective, the study aimed to observe the effects of the physiotherapeutic intervention through the fotobiomodulção therapy in a patient with nipple necrosis after prophylactic mastectomy.

\section{MATERIAL AND METHODS}

A Brazilian female with a necrosis of more than $40 \%$ of the nipple on the right breast after breast mastectomy and reconstruction was referee to Physical Therapy (PT). PT sessions were composed by manual lymph drainage, manual therapy for de AWS, exercises of strengh and flexibility, followed by LLLT with laser $660 \mathrm{~nm}, 2$ joules per point at every $1 \mathrm{~cm}$. Therapy was implemented for 12 times in total, performed from may 2016 untill June 2016. A reevaluation was performed monthly from July 13,2016, untill november 2017

\section{CASE REPORT}

A 36-year-old Brazilian female was referred to our institution in may 2016 for Physical therapy for bilateral mastectomy surgery.

The patient received neoadjuvant therapy of 12 cycles of Taxol and 4 cycles of AC followed by hormone therapy with Letrozole e Zoladex and monthly denosumab.

In april 2016 she had bilateral modified mastectomy with reconstruction and placement of expanderin left breast and left axillary lymphadenectomy. The anatomopathological analysis confirmed the diagnosis of invasive ductal carcinoma in the Left breast: $6 \mathrm{~cm}$ grade 2 DCIS with $0.6 \mathrm{~cm}$ of grade 2 IDC with

LVI, 1/12 node positive. Positive LVI .Final breast surgical margins were free,. The axillary lymph nodes dissection showed signs of cancer (1/12). In addition, immunohistochemical staining of the tumor was positive for estrogen and progesterone receptors, and HER-2. BRCA mutation testing was negative. In the Right breast there was no pathology.

Bone scan confirmed hypermetabolic sternal bone lesion and slight hypermetabolic uptake in cervical LN and left axilla. In the last PET/ CT showed no evidence of metastatic disease.
Physical examination revealed shoulder low range of motion and bilateral axillary web syndrome (AWS). There was a necrosis of more than $40 \%$ of the nipple on the right breast. PT sessions were composed by manual lymph drainage, manual therapy for AWS, exercises of strengh and flexibility, followed by LLLT with red laser $660 \mathrm{~nm}$, energy 2 joules per point at every $1 \mathrm{~cm}$ in whole nipple.

Therapy was implemented for 12 times in total, performed from may 2016 until June 2016. A reavaluation was performed monthly from July 2016, until november 2017. The nipple healed and repigmented its color.

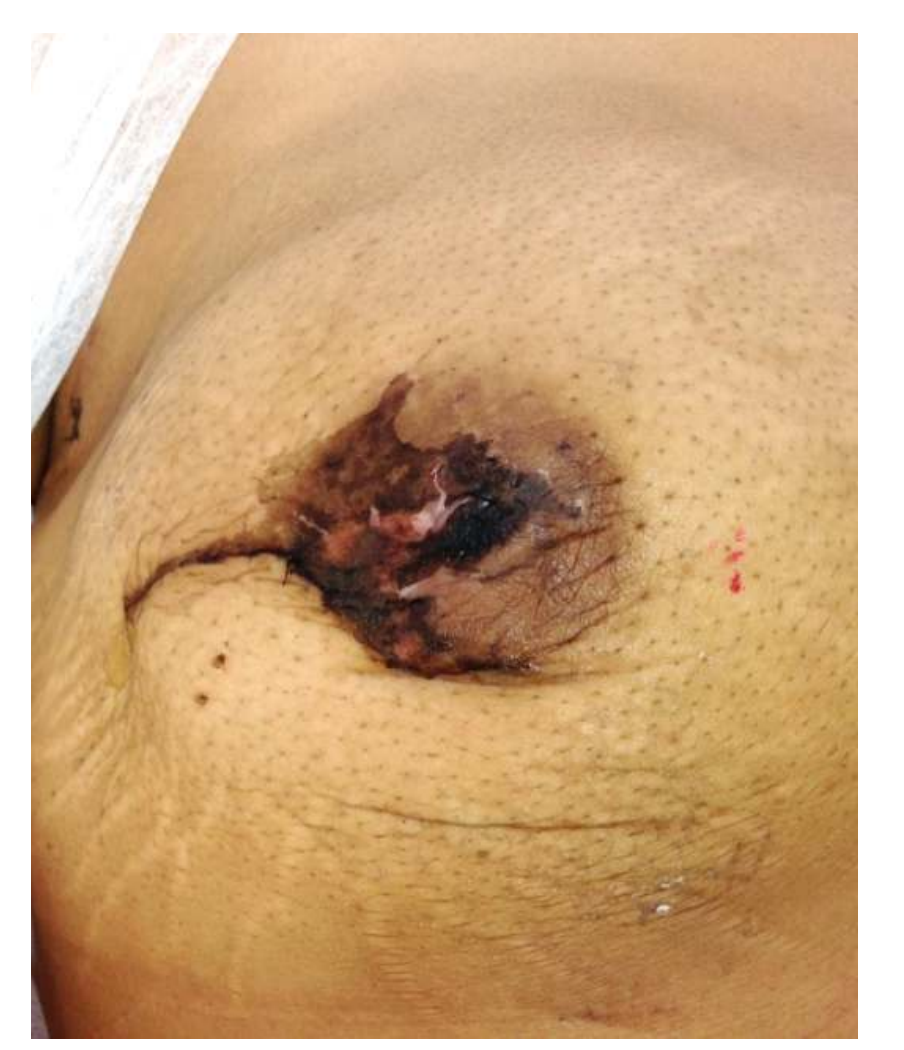

May $11^{\text {th }}$

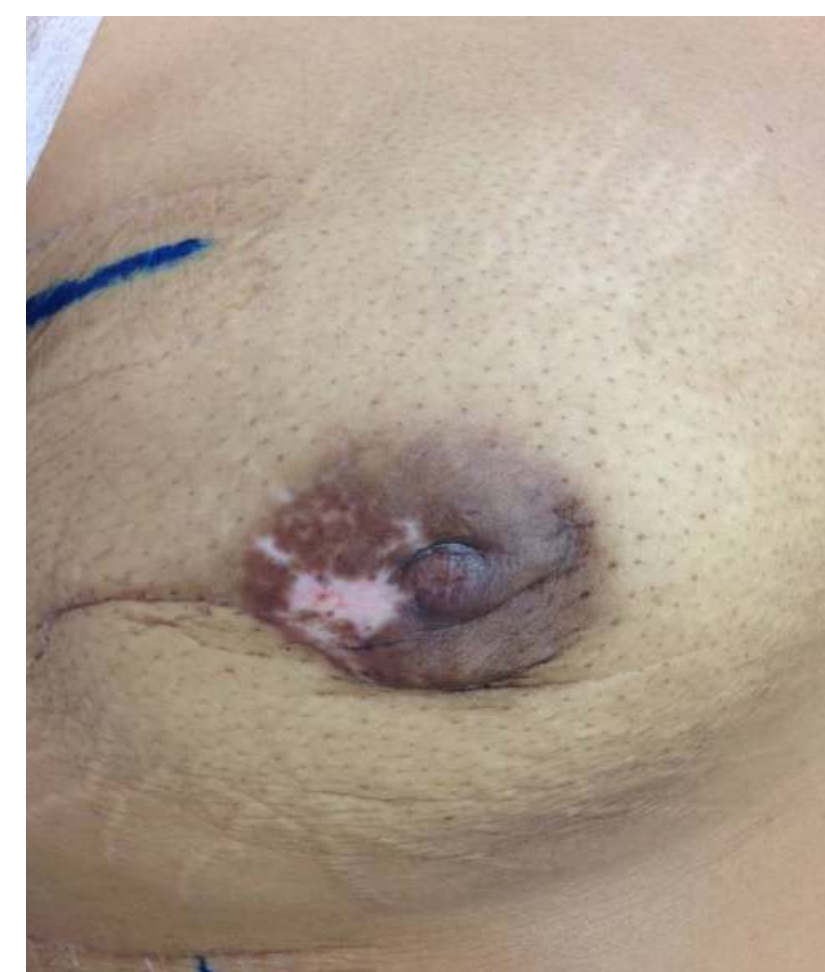

June $2^{\text {nd }}$

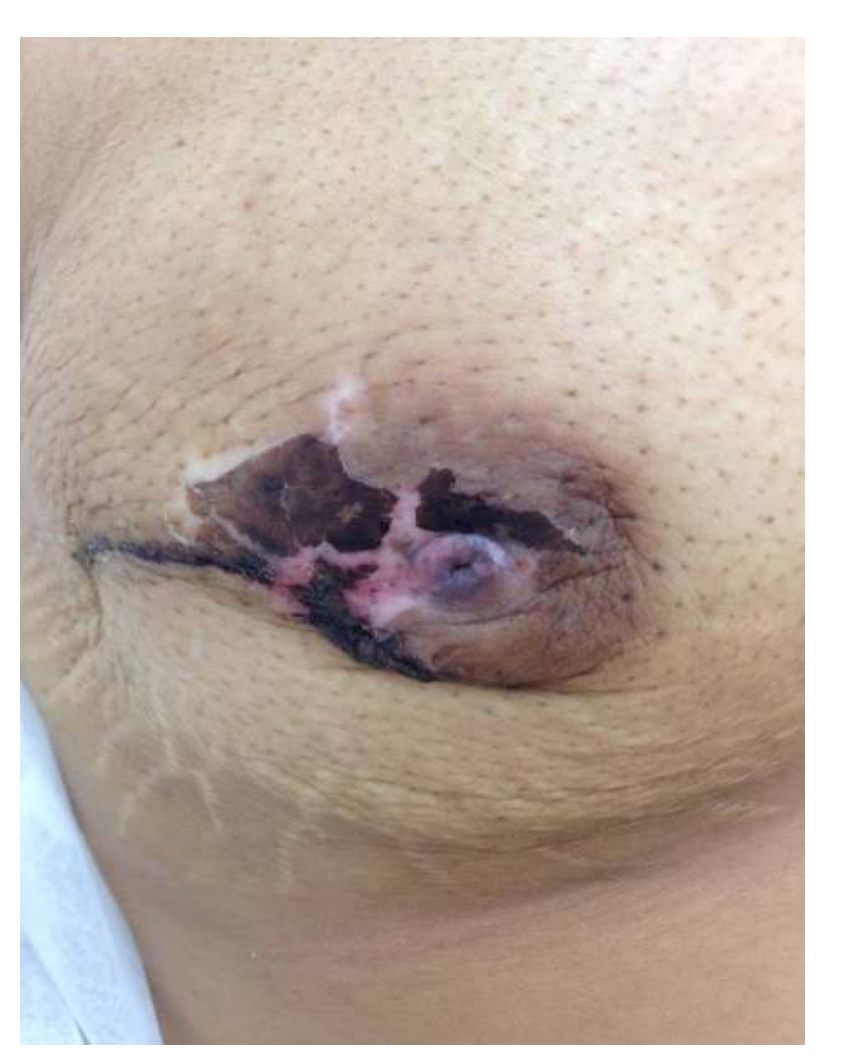

May $13^{\text {rd }}$

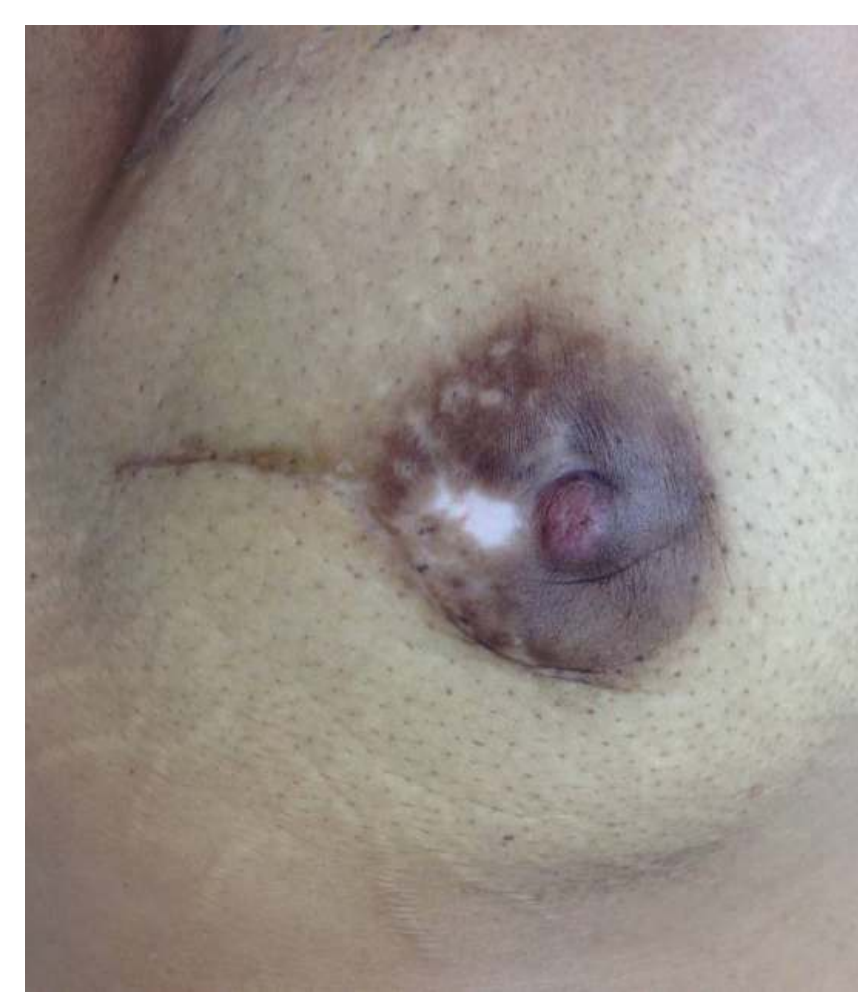

June 29 th

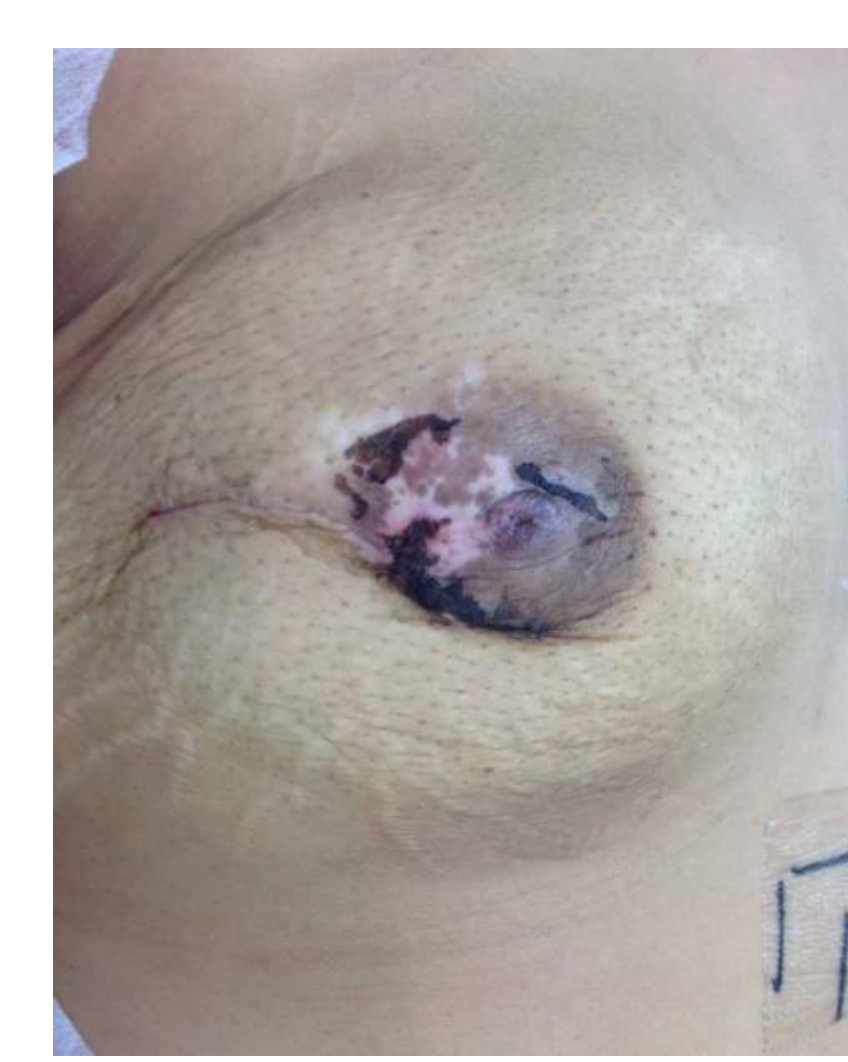

May $18^{\text {th }}$

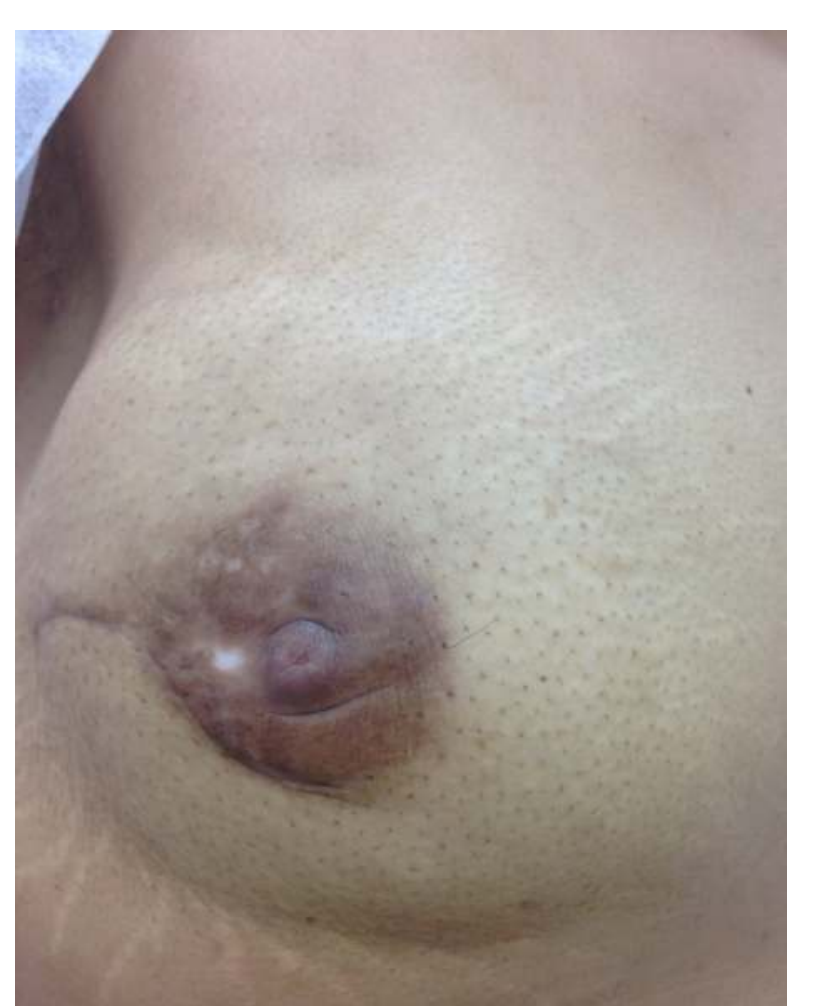

Aug $10^{\text {th }}$

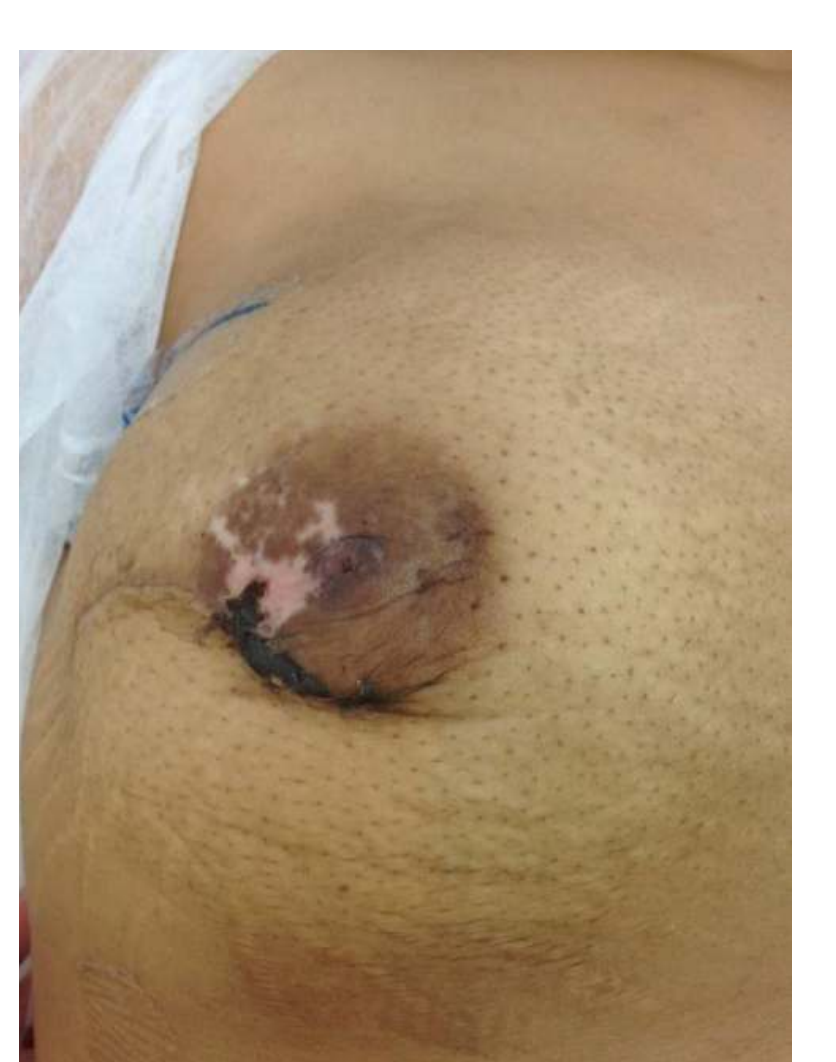

May $23^{\text {rd }}$

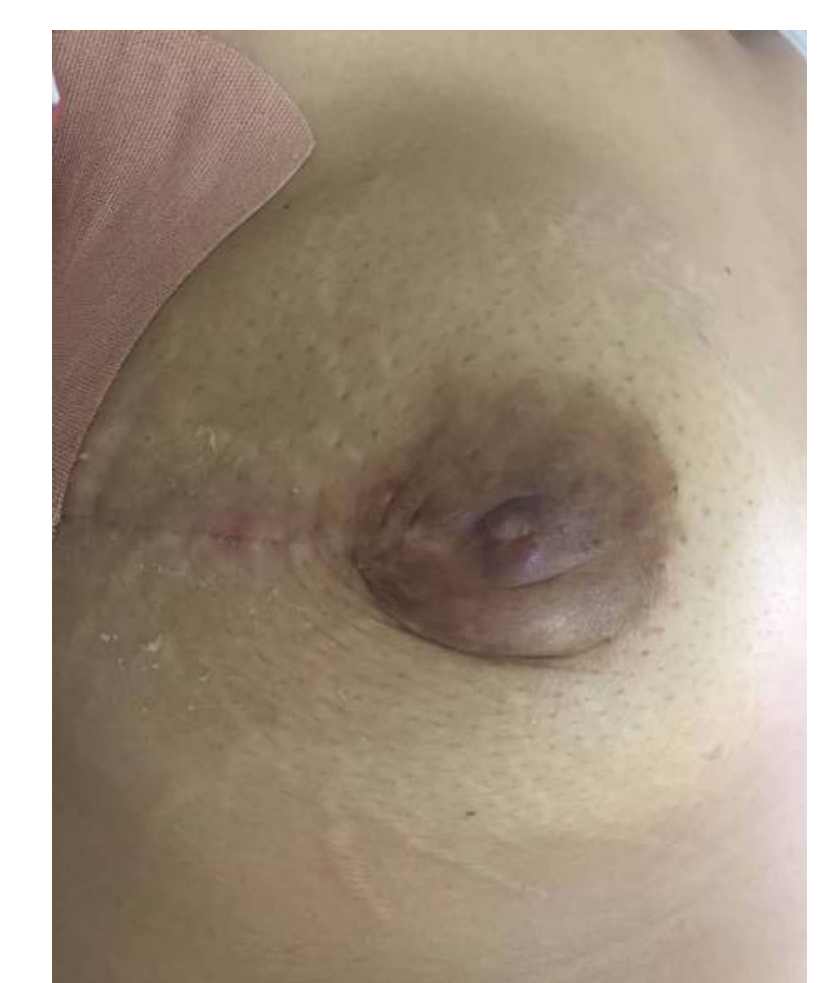

after 18 months

\section{CONCLUSION}

Specific research on physiotherapy for patients with nipple necrosis is scarce, we experienced that LLLT was helpful for wound healing. Confirmation of the sustained effects of LLLT was shown in a followup 18 months after the patient's first examination..

\section{REFERENCES}

1. Piper, Merisa, et al. "Total skin-sparing mastectomy: a systematic review of oncologic outcomes and postoperative complications." Annals of plastic surgery 70.4 (2013): 435-437.

2. Dent, Briar L., et al. "Nipple-areolar complex ischemia after nipplesparing mastectomy with immediate implant-based reconstruction: risk factors and the success of conservative treatment." Aesthetic Surgery Journal 34.4 (2014): 560-570.

3. Omar MT, Shaheen AA, Zafar H:A systematic review of the effect of lowlevel laser therapy in the management of breast cancerrelatedlymphedema.Support Care Cancer2012,20:2977-2984.

4. Bensadoun RJ, Nair RG. Low-level laser therapy in the prevention and treatment of cancer therapy-induced mucositis: 2012 state of the art based on literature review and meta-analysis. Curr Opin Oncol. 2012 Jul;24(4): 363-70. 